\title{
MOOD CHANGES IN PHYSICALLY ACTIVE MEN IN SITUATIONS OF IMAGINED DISCONTINUATION OF PHYSICAL EXERCISES AS AN INDICATION OF THE RISK OF ADDICTION TO PHYSICAL EXERCISES
}

\author{
Mood in the situation of imagined discontinuation of exercise
}

\author{
MONIKA GUSZKOWSKA, PAWE€ RUDNICKI \\ The Josef Pilsudski University of Physical Education in Warsaw, Faculty of Tourism and Recreation, \\ Department of Management and Organisation
}
Mailing address: Monika Guszkowska, The Josef Pilsudski University of Physical Education in Warsaw, 34 Marymoncka Street, 00-968 Warszawa, tel.: +48 228340431 ext. 571, fax: +48 228651080 ,
e-mail: mguszkowska@wp.pl

\begin{abstract}
Introduction. The phenomenon of addiction to exercise is one of the risks of systematically undertaken recreational physical activity. It is more common in men, especially those undertaking intense aerobic workout. The diagnostic criteria include the so called withdrawal symptoms expressed by deterioration of mood in the situation of discontinuation of exercise. The aim of this study was to determine mood changes in regularly exercising men in the situation of imagined discontinuation of exercise compared to the neutral situation, and their relation to the length of involvement in sports, the frequency and duration of exercise and the risk of addiction to exercise. Material and methods. The study involved 45 men aged 20-33 years who practice recreational jogging, combat sports, and exercising at the gym. Standard scales were used to test the mood: Profile of Mood States (POMS) and the Mood Adjective Check List (UMACL), measuring the emotional states in neutral situation and the imaginary discontinuation of exercise and the scale to assess the risk of dependence on exercise developed for the study. Results. The results show a significant deterioration of mood in the situation imagined discontinuation of exercise, as compared to the neutral situation. Its magnitude grows along with the length of the men's involvement in sports, but there were no significant associations with the frequency or duration of exercise. The risk of addiction to exercise is positively correlated to the mood deterioration and the length of involvement in sports. Young men who systematically exercise regularly expect a significant deterioration in their mood in a situation of discontinuation of exercise, which suggests that there is a risk of addiction to physical exercise.
\end{abstract}

Key words: physical activity, sports practice, addiction

\section{Introduction}

The benefits of exercise are well documented in the literature. Physical activity is a very important factor in prevention and treatment of many diseases and disorders, both somatic and psychological. Among the psychological effects, particular attention has been paid to the benefits in the emotional sphere, both emerging from one off effort, as well as in people who exercise on a regular basis. Physically active people are healthier, not only somatically, but also demonstrate much better frame of mind.

Regular physical exercise for the majority of those who exercise is therefore no doubt of a pro-health nature. Sometimes, however, it happens that physical activity begins to occupy a central place in the life of the individual, thus eliminating all other forms of leisure activities. Such people exercise regularly, regardless of the circumstances, even when they are ill, have suffered an injury or been banned by a doctor. Physical activity begins to dominate their lives, negatively affecting the other functional areas, such as job, family life or social relations $[1,2]$.

In order to describe this phenomenon, researchers use various terms such as exercise addiction, exercise dependence, obligatory exercise, compulsive exercising.
The incidence of addiction to exercise among people exercising regularly is not easy to determine. According to Allegre et al. [3], regardless of whether we use criteria similar to those of substance dependence or addiction modelled on behavioural criteria (activities) the incidence of addiction to exercise is about 5\%. Szabo and Griffiths [4] found that nearly $7 \%$ of sport science students were at risk of addiction, however the rate was significantly lower in the case of people exercising in fitness clubs (less than $4 \%$ of the respondents). Addiction to exercise is the most frequently reported in the case of people taking up of aerobic exercise (running, cycling, swimming), primarily male recreational athletes or former athletes [5].

The first researcher to put forward proposals of exercise addition criteria was Coverley Veale [6]. These included:

1. Narrowing the set of exercises leading to stereotyped patterns of training, repeated regularly at least once a day;

2. Giving an increasing importance and clear priority to exercise in relation to other forms of activity in order to maintain the pattern of exercises;

3. Increasing tolerance of the number of exercises performed in subsequent years;

4. Withdrawal symptoms associated with mood disorders after a break in the planned exercises; 
5. Avoidance or mitigation of withdrawal symptoms by further exercise;

6. Rapid return to the previous pattern of exercise after a long period without exercising.

The author also introduced distinction between primary and secondary addition. The first one is not associated with mental disorders and can be identified only by their exclusion, while the second one occurs in the course of eating disorders. In the research of 1995 Veale [2] slightly modified the criteria emphasizing stereotyped patterns of exercise and withdrawal symptoms. He treated mild addiction as something positive, or something of no special significance, according to him, moderate dependence begins to be a problem, while a serious one is associated with the risk of considerable difficulties in different areas of functioning.

Since the time of first reports of addiction to physical exercise $[7,8]$, there have been many studies describing the physical and psychological effects of the discontinuation of exercise by people exercising regularly. These include fatigue, weakness, pain, insomnia or trouble with sleeping, restlessness, increased anxiety and depression, irritability, nervousness, and mental discomfort [9-13]. These states, in varying degrees, are revealed at the earliest within 24-36 hours after the cessation of exercise $[1,14]$, although they can also be observed in the long term [15]. Withdrawal symptoms, manifested in both, the mental and the physical sphere are one of the main criteria for diagnosing addiction.

In conclusion, the researchers treating exercise addiction as a pathological phenomenon demonstrate two properties: neuroadaptation (tolerance and withdrawal symptoms) and adverse consequences (exercise despite medical contraindications) [3]. It should be noted that the primary syndrome of addiction to physical exercise has not been confirmed in the clinical sense, and is not a diagnostic category according to ICD-10 or DSM-IV.

For addiction to take place, physical exercise must constitute an activity providing positive reinforcement (pleasure) as well as "negative" (decreasing distress). As pointed out by Davis [16], both of these conditions are met in a small number of exercising people, so the risk of addiction in the general population is not large.

However, this phenomenon deserves attention because of the serious health consequences. In the case of people addicted to exercise the risk of injury and trauma increases, as they continue to exercise despite medical contraindications. Devoting much time exercises, they often neglect their professional duties, while their family relationships and friendships deteriorate.

Glasser [17] believes that for addition to take place, one must devote an hour a day to exercising for a sufficiently long period of time. It can be therefore expected that the risk of addiction grows along with the length of involvement in sports and increase in the frequency and duration of training individual exercises. The results of the study performed by Szabo et al. [18] indicate a positive correlation between addiction to physical exercise of joggers and the frequency of jogging, the distance run and the duration of training. The relationship between the volume of training and the addiction to exercise is likely to be reciprocal - high frequency, intensity and duration of exercise increase the risk of addition due to the perceived desirable consequences in the emotional sphere, it leads to increasing the volume of exercise to maintain the effect, which is defined as tolerance [3, 9] and is one of the indicators of addiction [19]. There are, however, such studies, which observed the phenomenon of addiction in people taking up exercise of small volume [20].

To determine the risk of addiction to exercise a number of diagnostic tools were developed, both universal ones [19, 21,
22] and ones designed for testing of people practicing certain sports, mostly jogging [23, 24], but also for example strength sports [25]. None of these tools has been adapted to the Polish conditions yet.

In studies on the phenomenon of addiction to exercise, recruiting subjects is a separate problem. People exercising regularly do not want to voluntarily give up their exercises [8], and observing withdrawal symptoms in people who are forced to cease exercising because of injury is difficult because of the summation of the negative consequences of the injury and the need to abandon the exercising [15, 26]. An attempt to overcome these difficulties can involve projective testing of the mood of people systematically exercising, in conditions of imaginary discontinuation of exercise. By modifying instructions in the diagnostic tools, one can instruct the subjects to imagine how they would feel if they had to cease their regular exercising for a while. The expectation of depressed mood in these conditions can be taken as an indicator of potential withdrawal symptoms in the affective sphere. This anticipation may be the result of previous experiences of the exercising person, who had suffered such symptoms, or appear as the result of processing information about emotional benefits of exercising.

The aim of this study was to determine the changes in moods of regularly exercising men in the situation imagined discontinuation of exercising, compared to the neutral situation and their relationship with the length of involvement in sports, frequency and duration of exercise and the risk of addiction to exercise.

\section{Material and methods}

The study involved 45 men aged 20-33 years who practice recreational jogging, combat sports, and exercising in the gym, each of the three study groups consisted of 15 people. Their involvement in sports ranged from one year to 12 years $(\mathrm{M}=5.72, \mathrm{SD}=4.382)$. The subjects trained for 2 to 6 times a week $(M=3.89, S D=1.172)$, the average duration of training ranged from 1 to 2.5 hours and was on average less than an hour and a half $(\mathrm{M}=1.43, \mathrm{SD}=0.313)$.

Standard tools for diagnosing emotional states were used in the study:

1. McNair, Lorr and Droppeleman moods profile (Profile of Mood States - POMS) in the Polish adaptation by Dudek and Koniarek [27], which defines the severity of seven emotional states, including five negative (anger, tension, confusion, depression, fatigue) and two positive (vigour and kindness);

2. Adjective Mood Scale (UMACL) of Matthews, Chamberlain and Jones in the Polish adaptation by Goryńska [28], which allows the measurement of three dimensions of root affect: hedonistic tone, energetic and tension excitation.

Both of them are characterised by good psychometric properties.

Both scales were used twice - with standard instructions, which asked about the mood in the last week, and after two days with instruction modified for these tests. The subjects were asked to imagine how they would feel if they did not exercise for two weeks.

In order to determine the risk of addiction to physical exercises, a $U$ scale was designed, consisting of 14 statements about the degree of involvement in the exercise ( 1 feel the need to train at least once a day), psychological benefits associated with them (After the workout, I feel much better), their willingness to continue in spite of illness or injury (I would continue exercising even with intense pain), and willingness to give up other activities in leisure time (I would not postpone 
a meeting with friends because of the training). The subjects responded to questions using a five-point scale: from 1 (strongly disagree) to 5 (strongly agree), with theoretical range being 14-70 points, while the results obtained by the respondents ranged from 35 to 60 points.

\section{Results}

Table 1 shows the results of the comparison of emotional states in two situations: neutral and imaginary discontinuation of exercising. The significance of differences was determined using the Student t test for dependent samples. The subjects expected a significant deterioration in mood in all dimensions, both emotional states as diagnosed by the POMS method and dimensions of mood as measured by UMACL. After a two week break in training men expect lower level of positive states (vigour, friendliness, hedonistic tone, energetic excitation), and higher level of negative state (anger, confusion, depression, fatigue, tension, tension excitation).

Table 1. Comparison of emotional states in the neutral position and the imaginary discontinuation of exercise $(n=45)$

\begin{tabular}{|c|c|c|c|c|}
\hline $\begin{array}{l}\text { Measurement } \\
\text { Variable }\end{array}$ & $\begin{array}{l}\text { Neutral situation } \\
\qquad(M \pm S D)\end{array}$ & $\begin{array}{l}\text { Imagined } \\
\text { discontinuation } \\
\text { of exercise } \\
\left(\mathrm{M}_{ \pm} \mathrm{SD}\right)\end{array}$ & $t$ & $p$ \\
\hline Anger & $11.54 \pm 5.80$ & $17.89 \pm 6.54$ & 6.923 & 0.000 \\
\hline Confusion & $8.11 \pm 3.53$ & $11.60 \pm 3.90$ & 7.276 & 0.000 \\
\hline Depression & $9.47 \pm 6.91$ & $19.27 \pm 7.01$ & 8.158 & 0.000 \\
\hline Fatigue & $9.42 \pm 4.75$ & $11.44 \pm 4.00$ & 2.770 & 0.008 \\
\hline Tension & $9.51 \pm 4.53$ & $16.20 \pm 5.20$ & 9.539 & 0.000 \\
\hline Vigour & $22.38 \pm 3.91$ & $13.36 \pm 3.41$ & 14.028 & 0.000 \\
\hline Friendliness & $18.78 \pm 3.60$ & $16.11 \pm 2.66$ & 5.296 & 0.000 \\
\hline Hedonistic tone & $31.67 \pm 2.91$ & $25.56 \pm 5.04$ & 6.677 & 0.000 \\
\hline Energetic excitation & $32.76 \pm 2.24$ & $24.82 \pm 4.19$ & 10.880 & 0.000 \\
\hline Tension excitation & $17.33 \pm 4.06$ & $20.56 \pm 3.86$ & 5.483 & 0.000 \\
\hline
\end{tabular}

Also indicators demonstrating decrease in the positive states by subtracting from the neutral situation result in imaginary discontinuation of exercise were calculated and the indicators demonstrating growth of negative states (result in a situation of discontinuation of exercise - neutral situation result). Looking for relationships between the degree of deterioration of mood in the situation imagined discontinuation of exercise and the indicator of physical exercise addiction risk, length of involvement in sports, training frequency and duration, linear correlation r- Pearson coefficients were calculated. Statistically significant correlation coefficients and ones reaching the level of trend are presented in Table 2.
Table 2. Relationships between the risk factor of addiction to exercise. length of involvement in sports and frequency of training and emotional states in a situation discontinuation of exercise and indicators of changes in emotional states $(n=45)$

\begin{tabular}{|c|c|c|l|c|c|}
\hline \multirow{2}{*}{} & \multicolumn{2}{|c|}{$\begin{array}{c}\text { Measurement in situation of imagined } \\
\text { discontinuation of exercise }\end{array}$} & \multicolumn{2}{|c|}{$\begin{array}{c}\text { Indicator of deterioration } \\
\text { in emotional state }\end{array}$} \\
\cline { 2 - 6 } & $\begin{array}{c}\text { Risk of } \\
\text { addiction }\end{array}$ & $\begin{array}{c}\text { Length of } \\
\text { involvement }\end{array}$ & Frequency & $\begin{array}{c}\text { Risk of } \\
\text { addiction }\end{array}$ & $\begin{array}{c}\text { Length of } \\
\text { involvement }\end{array}$ \\
\hline Anger & $0.491^{* *}$ & & & $0.427^{* *}$ & \\
\hline Confusion & & & & & \\
\hline Depression & $0.431^{* *}$ & $0.276^{\mathrm{t}}$ & & $0.533^{*}$ & $0.283^{\mathrm{t}}$ \\
\hline Fatigue & & & & $0.323^{*}$ & \\
\hline Tension & $-0.322^{*}$ & $0.273^{\mathrm{t}}$ & & & $0.297^{*}$ \\
\hline Vigour & & & & $0.312^{*}$ & \\
\hline Friendliness & $-0.515^{*}$ & & & $0.573^{* *}$ & $0.275^{\mathrm{t}}$ \\
\hline Hedonistic tone & & & $0.265^{\mathrm{t}}$ & & \\
\hline
\end{tabular}

${ }^{* *} \mathrm{p}<0.01 ;{ }^{*} \mathrm{p}<0.05 ;{ }^{\mathrm{t}} \mathrm{p}<0.1$

High risk of dependency on physical activity correlates positively with the level of anger and tension, and negatively with energetic excitation and kindness in the situation of imagined weekly discontinuation of exercises. The greater the risk of addiction the greater the expected mood deterioration after two weeks of discontinuation of exercises: greater increase in anger and tension and a decrease in vigour, energetic excitation and hedonistic tone.

Relationships with the length of involvement in sports are less numerous and far weaker. The length of involvement in sports is linked directly proportional to the level of tension and kindness in a situation of discontinuation of exercise. The longer it is the greater the decrease in vigour and energetic excitation and the increase in fatigue. The frequency of training is linked positively with the level of tension excitation in the event of discontinuation of exercise. There was no association between the number of training sessions per week and with indicators of changes in emotional states. The duration of a single training session is not linked with emotional states in the situation imagined discontinuation of exercise or the change indicators.

Also links between the risk of addiction to physical exercise and training experience and the frequency, duration and intensity of workouts were searched for. The risk of addiction increases as the length of involvement in sorts grows $(\mathrm{r}=0.658$, $\mathrm{p}<0.0001$ ), it is the only statistically significant relationship.

\section{Discussion}

The results indicate that men participating in the study, who regularly undertook recreational physical activity, expect a significant deterioration in mood (decrease in intensity of positive states and dimensions of mood and increased intensity of negative states and dimensions) in the imaginary situation of forced two-week break in exercising. This is consistent with the results of these studies, which determined the existence of negative consequences of discontinuation of exercise in the emotional sphere, such as increased levels of anxiety, fear and depression, irritability, nervousness, psychological and physical discomfort [2, 9-13]. These symptoms are treated as so called withdrawal symptoms and constitute diagnostic criteria for determining addition to physical activity [2, 3, 10, 19]. 
At this point it should be noted, that there was a significant difference in the procedure of previous studies and those presented herein. In these first ones the signs of withdrawal were usually monitored in volunteers, voluntarily quitting their exercise for the purpose of the studies or individuals forced to stop training due to injury. In our study, a procedure referred to as projection testing was used - men who train regularly were asked to imagine how they would feel if they could not exercise for two weeks. Therefore what the subjects recorded were not real, but imaginary mood states. Despite this, the results can be considered as an indirect indicator of a potential deterioration in mood in a situation of deprivation of physical activity.

The expectations of the subjects are a likely result of previously experienced mood swings due to cessation of physical activity. And if they did not experience anything like that - they were probably formed as a result of mood experienced when they systematically exercise, which in their opinion, is an emotional benefit of the exercise. As they expect a significant deterioration in mood, they must believe that physical exercise significantly improves it. On the other hand, as the respondents expected a deterioration in mood when they do not exercise, the reported increase the intensity of negative states and the decline in positive states, at least in part, are the effect of these expectations as to the mechanism of self-fulfilling prophecy.

Unfortunately, with the procedure used in the study we still cannot resolve the fundamental issue - i.e. is mood reduced to the initial level experienced by the individual when he has not yet undertaken systematic exercises, or does it fall below that level. In the first case there would only be withdrawal of the beneficial effects of regular exercise, and in the seconds case we would be certainly dealing with symptoms of withdrawal. These issues are possible to resolve only in sufficiently long experimental studies.

Results of many previous studies [29] have shown that regular physical exercise, especially of aerobic nature, leads to improved mood. These beneficial effects were observed regardless of sex and age of the people who exercise, both in healthy subjects and in clinical groups (patients with psychiatric disorders and those suffering from somatic illnesses). In order to clarify the effect of exercise on the emotional sphere, researchers refer to both, the physiological and psychological mechanisms. According to the endomorphic hypothesis, improvement in mental state after exercise is caused by increased levels of beta-endorphins. The monoamine hypothesis, in turn, refers to the fact that exercise leads to increased levels of neurotransmitters. The anxiolytic effect of physical exercise is often explained by the increase in body temperature after intense exercise. It is also known that regular exercise reduces the reactivity of the hypothalamic - pituitary - adrenal axis activated in stressful situations. The possible psychological mechanisms include distraction from the worries and troubles, increase in the perception of self-efficacy, and increase selfesteem, especially in the physical sphere [29, 30]. The very same mechanisms that are responsible for positive changes in mood in people exercising, can lead to addiction to exercise.

Depressed mood is more strongly marked in the case of energetic excitation and vigour - i.e. positive emotional states associated with the level of activation. This suggests that discontinuation of exercise can lead to lower activation falling levels below optimum, leading probably to a deterioration of efficiency. Perhaps it is to do with the decreased reactivity of the autonomous nervous system observed in individuals who regularly exercise. This lowers the base level of arousal. A person who exercises, wanting to achieve the optimal level of activation has to provide more and stronger stimulation - which implies more and more exercising [see 31].

The results show a relationship between the risk of addiction to physical activity and mood in a situation of discon- tinuation of exercise and mood in situations of imaginary discontinuation of exercise and the indicators of deterioration. They occur in the majority of the diagnosed emotional states and mood dimensions, both positive and negative. The greater the risk of addiction to exercising, the greater the expected mood deterioration during a break in training, is expected by the subjects. The strongest relationships were found in the case of anger, tension and energetic excitation. Previous studies have shown that in people addicted to exercise in a situation of deprivation, the level of tension, anxiety and depression, irritability and nervousness increase [2, 9-13]. It is difficult at this time to determine why there were no associations with indicators of depression and tension. These issues require further study.

The obtained results do not confirm the previously observed link between addiction to exercise and frequency and duration of training [18]. Only the length of involvement in sport correlates positively with the indicator of addiction. This partly confirms conjectures the expectations of Glasser [17] that in order to get addicted, one needs to exercise long enough (both, in the sense of length of involvement in sports and duration of exercise). It may be recalled that Glasser treated addiction to exercise as something positive and indicated the conditions for its occurrence.

The study also showed fewer and weaker than expected relationships between indicators of mood in the situation imagined discontinuation of exercise as well as deterioration thereof and the length of involvement in sports. Although their direction is predictable - the greater the length of involvement in sport, the more pronounced the discomfort, but in most cases they only reach the level of trend. Frequency of exercise correlates only with tension excitation and the duration of individual exercises are not linked with indicators of mood. The results obtained do not support the belief that withdrawal symptoms are more strongly marked in men who train for longer and with greater frequency. This may result from the applied procedure used to diagnose mood states. Neither can one rule out the existence of a curvilinear dependence, which is difficult to grasp with statistical analysis methods used.

\section{Conclusions}

The obtained results indicate that people exercising regularly expect deterioration in mood in a situation of discontinuation of exercise. If the level of expected mood deterioration is significant, it may indicate a risk of addiction to exercise. The results suggest that this risk may increase along with the length of involvement in sports. However, no relationship between deterioration in mood and frequency as well as duration of exercise was found.

\section{Literature}

1. Sachs, M.L. \& Pargman D. (1997). Running addiction. In M.L. Sachs \& G.W. Buffone (Eds.), Running as therapy: An integrated approach (pp. 231-254). New Jersey: Jason Aronson.

2. Veale, D. (1995). Does primary exercise dependence really exist? In J. Annett, B. Cripps \& H. Steinberg (Eds.), Exercise addiction. Motivation and participation in sport and exercise (pp. 1-5). Leicester: The British Psychological Society.

3. Allegre, B., Souville M., Therme P. \& Griffiths M. (2006). Definitions and measures of exercise dependence. Addiction Rev. Theory 14, 631-646.

4. Szabo, A. \& Griffiths M.D. (2007). Exercise addiction in British sport science students. Int. J. Mental Health Addiction 5, 25-28. 
5. Mędraś, M. \& Bidzińska B. (2004). Exercise dependence. In M. Mędraś (Ed.), Sports medicine (pp. 119-121). Warszawa: Medsportpress. [in Polish]

6. De Coverley Veale, D.M.W. (1987). Exercise dependence. Br. J. Addiction 82, 735-740.

7. Little, J.C. (1969). The athlete's neurosis: A deprivation crisis. Acta Psychiatrica Scand. 45, 187-197.

8. Baekland, F. (1970). Exercise deprivation: Sleep and psychological reactions. Archives General Psychiatry 22, 365-369.

9. Morgan, W.P. (1979). Negative addiction in runners. Phys. Sports Med. 7, 57-70.

10. Griffiths, M.D. (1996). Behavioral addiction: An issue for everybody? J. Workplace Learning 8, 19-25.

11. Morris, M., Steinberg H., Sykes E.A. \& Salmon P. (1990). Effects of temporary withdrawal from regular running. J. Psychosom. Res. 34, 493-500.

12. Berlin, A.A., Kop W.J. \& Deuster P.A. (2006). Depressive mood symptoms and fatigue after exercise withdrawal: the potential role of decreased fitness. Psychosom. Med. 68, 224-230.

13. Glass, J.M., Lyden A.K., Petzke F., Stein P., Whalen G., Ambrose K. et al. (2004). The effect of brief exercise cessation on pain, fatigue, and mood symptom development in healthy, fit individuals. J. Psychosom. Res. 57, 391-398.

14. Sachs, M.L. \& Pargman D. (1979). Running addiction: a depth interview examination. J. Sports Behav. 2, 143-155.

15. Mondin, G.W., Morgan W.P., Piering P.N., Stegner A.J., Stotesbery C.L., Trine M.R. et al. (1996). Psychological consequences of exercise deprivation in habitual exercisers. Med. Sci. Sports Exerc. 28, 1199-1203.

16. Davis, C. (2000). Exercise abuse. Int. J. Sport Psychol. 31, 278-289.

17. Glasser, W. (1976). Positive Addiction. New York: Harper and Row.

18. Szabo, A., Frenkl R. \& Caputo A. (1997). Relation between addiction to running, commitment to running, and deprivation from running: A study on the Internet. Eur. Yearbook Sport Psychol. 1, 130-147.

19. Hausenblas, H.A. \& Symons Downs D. (2002). How much is too much? The development and validation of the exercise dependence scale. Psychol. Health 17, 387-404.
20. Bamber, D.J., Cockerill I.M., Rodgers S. \& Carroll D. (2003). Diagnostic criteria for exercise dependence in women. Br. J. Sports Med. 37, 393-400.

21. Terry, A., Szabo A. \& Griffiths M.D. (2004). The exercise addiction inventory: A new brief screening tool. Addiction Res. Theory 12, 489-499.

22. Pasman, L. \& Thompson J.K. (1988). Body image and eating disturbances in obligatory runners, obligatory weightlifters, and sedentary individuals. Int. J. Eat. Disord. 7, 759-769.

23. Rudy, E.B. \& Estok P.J. (1989). Measurement and significance of negative addiction in runners. West. J. Nurs. Res.11, 548-558.

24. Chapman, C.L. \& Decastro J.M. (1990). Running addiction measurement and associated psychological characteristics. J. Sports Med. Phys. Fitness 30, 283-290.

25. Smith, D.K., Hale B.D. \& Collins D. (1996). Measurement of exercise dependence in bodybuilders. J. Sports Med. Phys. Fitness 38, 66-74.

26. Chan, C.S. \& Grossman H.Y. (1988). Psychological effects of running loss on consistent runners. Percept. Mot. Skills 66, 875-883

27. Dudek, B. \& Koniarek J. (1987). Adaptation of Profile of Mood States (POMS) by D.M. McNair, M. Lorr \& L.F. Droppleman. Przegląd Psych. 3, 753-762. [in Polish]

28. Goryńska, E. (2005). UWIST Mood Adjective Check UMACL by G. Matthews, A.G. Chamberlain, D.M. Jones. Manual. Warszawa: Pracownia Testów Psychologicznych PTP. [in Polish]

29. Guszkowska, M. (2004). The influence of exercises on anxiety, depression and mood states. PsychiatriaPolska 37, 611-620. [in Polish]

30. Guszkowska, M. (2009). Age and exercise duration as determinants of the effect of single bout of exercise on state anxiety in women. Medicina Sportiva 13, 125-130.

31. Guszkowska, M. (in press). Exercise dependence - symptoms and mechanisms. Psychiatria Polska. [in Polish]

Submitted: November 2, 2011

Accepted: January 24, 2012 